\section{CHANGES IN THE PRACTICE OF CONTRACEPTIVE PREVALENCE - AN OBSERVATIONAL STUDY}

\author{
Rabeya Akther ${ }^{1}$, Hasina Afroj ${ }^{2}$, Sayeeda Sultana ${ }^{3}$
}

\section{Abstract}

Family planning is an essential tool for reducing fertility rate. An increase in contraceptive prevalence rate results in reduction of population growth, which in turn contributes significantly to the improvement of people's health. It is a cross-sectional, descriptive type, observational study done during April-July 2007 in a large Medical Centre. Reproductive history was used as research instrument for data collection. The present study aimed at exploring Contraceptive prevalence and related issue among service holder and regulation of fertility among them. Two thirty one (231) women (childbearing age ) were selected randomly to find out their contraceptive prevalence. Eighty four ( $n=197)$ percent women need family planning service .

Among them 87.82 percent $(\mathrm{N}-173)$ of the respondents use any method of contraception. 79.76\%(N-138) women use modern method and 20.23 percent( $\mathrm{N}-35$ ) women use natural method .

Thirty three(33.53 \%)percent couple practice barrier method, twenty two(22.54\%) percent use oral pill, female sterilization is 9.25percent,injectable(DMPA) 5.78 percent,7.97percent mixed method.

There is progressive decline in oral pill use from 55\% to $26 \%$. Fertility rate, menstruation regulation is lower among servicing women. Education, empowerment and social position of women help to reduce fertility.

\section{Introduction:}

Optimum period for child delivery, prevention of unwanted pregnancy by safe contraception, and birth of wanted children are known to be the main directions in family planning. Family planning not only offer contraceptive benefit, it also ensure improvement in women's health, child health ,decrease infant and maternal death, decrease population growth and ultimately enhance the socio economic development. Fertility status (fecundity) is largely determined by age at marriage, age at $1^{\text {st }}$ child birth, birth space, and use of contraceptives. These variables are indirectly regulated by income, nutrition, housing, education and medical care of the people. There are evidenced that conditional cash transfer or improvement in socio economic condition have unintended effect on fertility control. ${ }^{1,2}$

1. Assist. Chief Medical Officer, Bangladesh Bank Medical Center, Dhaka, Bangladesh. Corresponding Author email: rabeyrakther@ yahoo.com

2. Associate Professor,Department of Obstetrics and Gynecology, Rajshashi Medical Collage Hospital, Rajshashi.

3. Assistant Professor, Department of Obstetrics and Gynecology, BSMMU.
Bangladesh's population estimated to be 143.91 million and is growing at a rate of $1.42 \%$ per annum. ${ }^{3}$ Bangladesh has achieved this progress against the backdrop of low literacy rate, low status of women and low income per capita and so on. Women of reproductive age group (15-49years) represent $46 \%$ of the total female population. Contraceptive prevalence (CPR) only $56 \%$.But total fertility rates across the countries is 2.7 (ranges from3.3-8.7) percent ${ }^{4,5}$

Total fertility rate in Bangladesh decline sharply over the last 37 years from 6.3 births per women in1971-1975 to 2.7 births per women in 2004-2006 (4, 5). For reduction of total fertility rate, family planning plays crucial role (7) C Contraceptive prevalence rate in Bangladesh increase slowly over the last 37 years from 8\% in 1975 to $56 \%$ in -2007 (4).During this period improvement in maternal malnutrition (BMI less than $18.5 \mathrm{~kg} / \mathrm{sq} \mathrm{m}$ ) $52 \%$ in $1996-97$ to $23.5 \%$ in 2007(4). Changes in adult literacy rate $51.6 \%$ in 2004(3) and increase in per capita income is 40\%.(7) By studying the reproductive history, size of family, son/ daughter preference, need for another child and contraceptives prevalence can be assessed and it would be helpful in formulating an intervention in order to decrease the fertility rate in Bangladesh. The present study aimed at exploring Contraceptive prevalence and related issue among service holder. The reason for non using contraceptives and the experience they gained after using different contraceptives would indicate the pathway to lower fertility rate in the society .This study would help in planning a strategy that could raise $\mathrm{CPR}$ and reduce the total fertility rate.

\section{Material and Methods:}

It is a cross-sectional, descriptive type, observational study done during April-July 2007 in Bangladesh Bank Medical Centre, Motijheel. During this period (April -July 2007) 4015 patients visited for general health care, consultation, ante natal care and gynecological care. Their history is taken. All patients asked for age, how long they are married, marital age of the women, age at 1st birth, number of living children, birth space, dead children, menstruation regulation and abortion, contraceptive methods, menstrual history, desire for future pregnancy and why they need another child. 231 women ( childbearing age group) were selected randomly to find out their contraceptive prevalence / fertility control. Simple random sampling technique was employed to collect data. Interviewer-administered structured questionnaire (Reproductive history) was used as research instrument for data collection. Collected data was then checked, cleaned, coding and editing was done properly. Finally data was entered into the computer for statistical analysis by using MS EXCEL. Patient's verbal permission was taken for publication and presentation. 
Characteristics of population: The respondents are working in this institute and have regular income, housing, education, transport and medical facility. Respondents are categorized according to their Income\& service.

- $\geq 10000 /$ taka ( $\mathrm{A}=$ House wife, $\mathrm{a}=$ Servicing women)

- $\geq 7000 /$ taka ( $\mathrm{B}=$ House wife, $\mathrm{b}=$ Servicing women)

- $\geq 5000 /$ taka $\quad(\mathrm{C}=$ House wife, $\mathrm{c}=$ Servicing women $)$

- $\geq 3500 /$ taka $\quad(D=$ House wife,$d=$ Servicing women)

They have health and family planning facilities, day care facility, limited emergency management facility, day care center for preschool children. Registered physician (10 doctors), registered nurse (3), medical assistant, pharmacist (10), family welfare visitor (1) are present there .Availability and utilization of private hospital care are more. Response of the couple about planned family indicated that 85\% couple desired to keep family small.

\section{Observation \& Results:}

About thirty percent (29.87\% )women are service holder and $70.13 \%$ women are house wife. Table 1 shows the distribution of women according to income and service.

Table-I: Respondents are categorized according to their Income\& service.

\begin{tabular}{lcccc}
\hline Class & & House wife & Servicing women & Total \\
\hline A & a & 71 & 29 & 100 \\
B & b & 41 & 30 & 71 \\
C & c & 18 & 6 & 24 \\
D & d & 32 & 4 & 36 \\
\hline Total & & $162(70.12 \%)$ & $69(29.87 \%)$ & $231(100 \%)$ \\
\hline
\end{tabular}

Table-2 shows the age specific distribution of women. The mean age of the respondents' was 37(18-49) years and $16.44 \%$ of women belonged to age group 21-30years, 55.56\% belonged to age group31-40years and $27.56 \%$ belonged to age group 4149 years. Only 17.33 percent women belong to peak reproductive age group.

Table-II: Age specific distribution of women

\begin{tabular}{lc}
\hline Age range & Number of women \\
\hline Less than 20yrs & $2(0.89 \%)$ \\
$21-30 y e a r s$ & $37(16.44 \%)$ \\
$31-40$ years & $125(55.56 \%)$ \\
41-49years & $62(27.56 \%)$ \\
\hline
\end{tabular}

Table 3 shows the demographic characteristics of women. Mean age at marriage is $18.24(13-28)$ years .Mean age at first birth is
21.46(18-33) years. First birth space 4.29 years and second birth space is 4.75years. Average number of children per women is 2.35. Average number of children per house wife is 2.65 and per service holder women is 1.88 .

Table-III: Demographic characteristics of respondents

\begin{tabular}{lc}
\hline Indicators & Results \\
\hline Age (Year) & $37(18-49)$ years \\
Weight (Kg) & $62.2(84-36)$ \\
CPR (\%) & 79.76 \\
Average no. of living child/family & $2.35(2-6)$ \\
Mean age at marriage (Year) & $18.24(13-28)$ \\
Mean age at 1 $1^{\text {st }}$ birth (Year) & $21.46(14-33)$ \\
$1^{\text {st }}$ birth space (Year) & $4.29(2-10)$ \\
$2^{\text {nd }}$ birth space (Year) & $4.75(1-11)$ \\
\hline
\end{tabular}

Table 4 shows Obstetric profile of the respondents. $16.45 \%$ couples had one child, $41.56 \%$ had two children, $22.51 \%$ had three children and, $11.26 \%$ had four children and 3.46\% had five or more children.

Table-IV: Obstetric profile of the respondents

\begin{tabular}{lc}
\hline No of children & Percentage of couples \\
\hline 1 child & $16.45 \%$ \\
2 children & $41.56 \%$ \\
3 children & $21.51 \%$ \\
4 children & $11.26 \%$ \\
5 or more children & $3.46 \%$ \\
\hline
\end{tabular}

Table 5 shows comparative distribution of children among servicing women vs house wife. Eight couples have no child. 11.16 of percent couple have intention for pregnancy due to incomplete family, son preference, daughter preference, company for sibling and protection of wealth .Some couples have no intention for another child though their family is incomplete because of maternal service, disease, maternal advanced age, second marriage and hysterectomy. Table 6 shows age specific distribution of contraceptives. Women of 21-30 years group practice condom and oral pill. Women of 3140 years age group practice mainly condom, oral pill and natural method. Women of 41-49 years age group practice mainly natural method, then oral pill and condom. Few women practice injection and sterilization. Some women are reluctant about the use of contraceptive because of their present life style offer protection. Only 30 (15.15\%) women need 50 menstruation regulations .Prevalence of menstruation regulations and use of emergency pill is less. 
Table-V: Comparative Distribution of children-Servicing women vs. House wife

\begin{tabular}{|c|c|c|c|c|c|c|c|c|c|c|c|}
\hline \multicolumn{2}{|l|}{ Class } & \multicolumn{2}{|c|}{ 1child } & \multicolumn{2}{|c|}{ 2child } & \multicolumn{2}{|c|}{ 3child } & \multicolumn{2}{|c|}{ 4child } & \multicolumn{2}{|c|}{ 5child } \\
\hline $\mathrm{a}$ & A & 5 & 12 & 18 & 24 & 3 & 21 & 0 & 10 & 0 & 2 \\
\hline $\mathrm{b}$ & B & 3 & 10 & 20 & 16 & 4 & 8 & 1 & 6 & 0 & 1 \\
\hline c & C & 2 & 4 & 1 & 4 & 3 & 7 & 0 & 0 & 0 & 2 \\
\hline d & D & 0 & 2 & 2 & 11 & 2 & 4 & 0 & 9 & 0 & 6 \\
\hline 1.87 & 2.56 & \multicolumn{2}{|c|}{$38(16.45 \%)$} & \multicolumn{2}{|c|}{$96(41.56 \%)$} & \multicolumn{2}{|c|}{$52(21.51 \%)$} & \multicolumn{2}{|c|}{$26(11.26 \%)$} & \multicolumn{2}{|c|}{$11(3.46 \%)$} \\
\hline
\end{tabular}

Table-VI: Age specific distribution of CONTRACEPTIVES

\begin{tabular}{lccccccc}
\hline AGE & OCP & Condom & Injection & Sterilization & Natural & Cu-T & Total \\
\hline $21-30 y r s$ & 6 & 13 & 5 & 2 & 0 & 1 & 27 \\
$31-40 y r s$ & 26 & 42 & 5 & 7 & 22 & 2 & 104 \\
$41-49 y r s$ & 5 & 5 & 0 & 7 & 12 & 2 & 31 \\
\hline Total & $37(22.54 \%)$ & $60(33.53 \%)$ & $10(7.58 \%)$ & $16(9.25 \%)$ & $34(20.23 \%)$ & $5(2.31 \%)$ & 162 \\
\hline
\end{tabular}

Figure 1 shows Contraceptive prevalence among respondents. 84.19 percent ( $\mathrm{N}-197)$ women need family planning service. About 87.82 percent $(\mathrm{N}-173)$ of the respondent use any method of contraception. $79.76 \%(\mathrm{~N}-138)$ of married women use modern method and 20.23 percent( $\mathrm{N}-35$ ) women use natural method .Thirty three(33.53\%)percent of the couple use barrier method, twenty two(22.54\%) percent use oral pill, female sterilization is 9.25percent,injectable(DMPA) 5.78 percent,7.97percent mixed method . Figure 2 shows year specific use of contraceptive in this center from1996-2007(11years study). Figure 3 shows comparison between present study\& national findings.

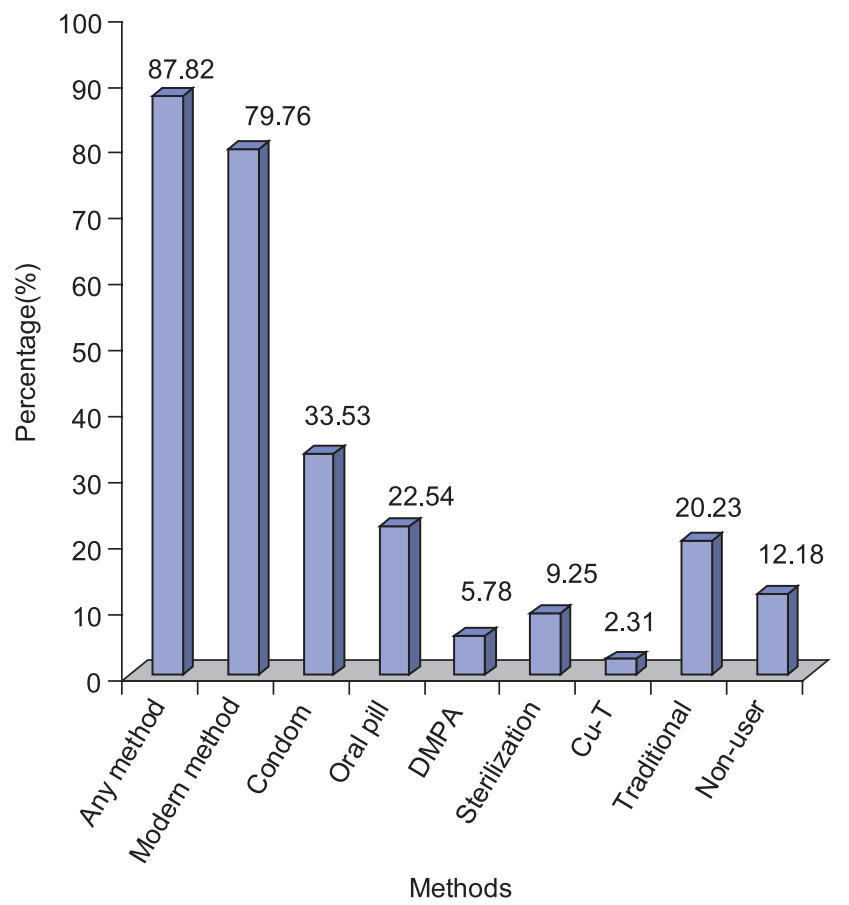

Fig.-1: Contraceptive prevalence among the Respondents

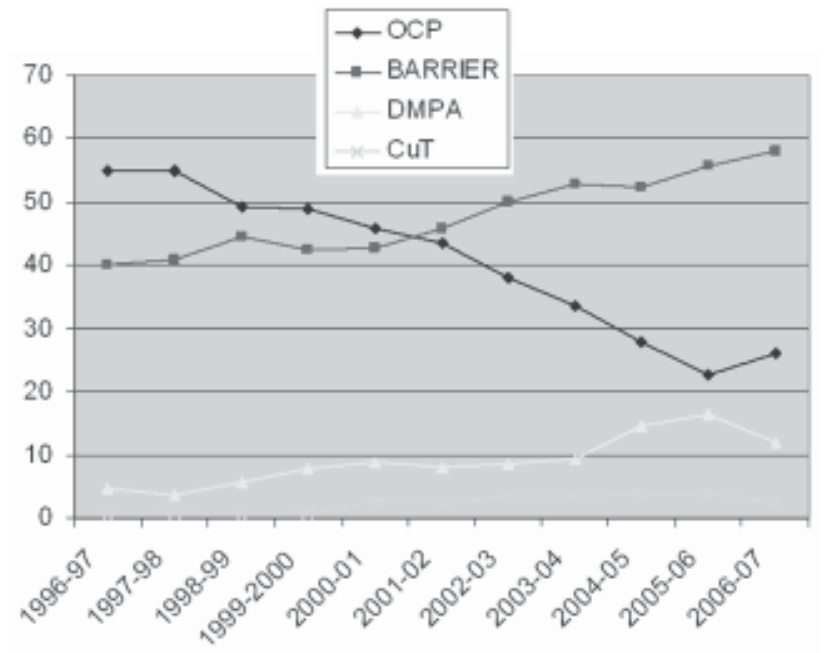

Fig.-2: Year specific use of contraceptive from19962007(11years record) in this centre.

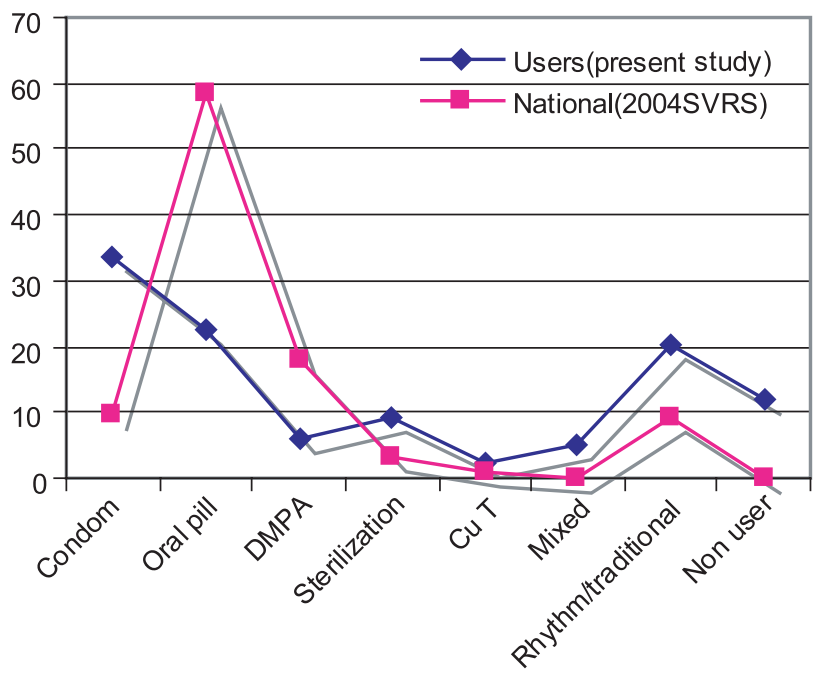

Fig.-3: Comparison between present study\& national study 


\section{Discussion:}

A women's health is intricately entwined with her social status that in turn involves a complex set of interrelated factors. Those factors include her income, employment, education, health and fertility and society's perception of her role in the family and community. $(2,3)$ From the study it was found that mean age at marriage is 18.24(13-28) years. It is equal with legal age of marriage (7). Mean age at first birth is 21.46(18-33) years .Comparison with data from sources show that the age at which women in Bangladesh have their first child has increased steadily over time. For example, in 1975, the median age at first birth among women age 20-24 was 16.8 , rising to 18.0 in 19911993, 18.4 in 1996-97 and 18.7 in 1998-2000.(8) A rise in median age at first birth is typically a sign of transition to lower fertility levels. In the present study 31.58\% women became pregnant or mother in adolescent (15-19 years) life. This finding is similar like our national findings. $(7,9)$ Number of children per women 2.36 but number of children among servicing women is 1.87 and house wife is 2.56(7). Fertility rate is less among servicing women. In the present study, 87.82percent married women need a method of family planning .Modern method are much more widely used ( $79.76 \%$ of married women) than natural method (20.35\%). The 2001 BMMS indicates that 50\% of currently married women in Bangladesh are using a method of family planning, 44\% women are using Modern method and $6 \%$ using natural method.(8) In this study it is showed that 33.53 percent couple use barrier method of contraception but in Bangladesh 10.6 percent couple use barrier method of contraception.$(3,4)$ This study also showed that there is progressive decline in oral pill use from 55\% to $26 \%$ over the last 11years( 1996-2007). But there is progressive increase in condom, injection and cupper T utilization and it is higher than national levels .Continued publicity against HIV and AIDS and increasing awareness of the people make use of condom more popular. Use of emergency contraceptive pill is also less. Only 71 couple during the last 4 (four) years receive emergency contraceptive pill. One third users complaining of rupture of condom and others are non user. Menstruation regulations (MR) are more prevalent among house wife than servicing women and fertility rate is lower among servicing women. Couple have negative attitude towards pill. They think pill causes scanty menstruation, weight gain and fear of malignancy.

$20.23 \%$ couple practice natural method and among them incidence of MR are less. Natural method is not very much effective. But couples education and responsibility make the method more effective .Adherence with the methods offers best result. Long term contraceptive method is not much effective for fertility reduction as well as population control because of poor acceptance. Nationally only 21.1 percent couple practice permanent method. (3) At present contraception and nature alone cannot control the population in developing countries. To achieve desired fertility rate (0 growth potential) women's education and empowerment is very essential. Urbanization, economic stability, educated environment and recreational facility helps the couple to keep family small. It improves family and social status. Women spent a large portion of their time in child caring. They are aware and try to avoid pregnancy. In this way, maternal and children morbidity and mortality are reduced. Contraceptive make couples more responsible and it promote better quality of life by helping families to use their resources for food, housing, schooling and medical care. Family planning provides alternative strategy to reduce maternal mortality. $(10,11)$ Hemorrhage, septic abortion, eclampsia, obstructed labor and infection are important cause of maternal death .(12,13) It is the sequels of pregnancy. Safe birth practice prevents only obstructed labor and labor related death. It is not sufficient to prevent total maternal mortality. To decrease MMR, (hemorrhage, septic abortion, eclampsia, obstructed labor and infection) control of fertility and encouragement of contraceptive prevalence is very essential.

Population program costs are relatively modest, typically amounting to less than five percent of national health budgets, and less than o.1 percent of government expenditures. (2) Women's empowerment and autonomy in reference to women's status have been interchangeably to denote women's independence at various levels. The assumption is common that education leads to autonomy, that it lets women to stand up to their husband and provides them with means to learn about fertility control and make effective use of health care delivery system.(14)

\section{Conclusion:}

Family planning helps to create favorable conditions for socioeconomic development, and improve educational performance. Minimum regular income, housing, education and medical facility offer family stability (1) and it has unintended effect on fertility. Education and social position makes one more responsible. Servicing women (empowerment) are more eager to keep family small.

\section{Reference:}

1. Guy Stecklov, Paul winters, Jessica Todd and Ferdinando Regilia. Unintended effects of poverty programmes on childbearing in less developed countries: Experimental evidence from Latin America, Population Studies, A Journal of Demography 61(2):125-140. July2007

2. Health, Population and Development in Asia and the Pacific: Asian Development Bank, Manila 1991, page 44. 
3. Sample vital registration System (SVRS), BBS, 2006

4. Bangladesh Demographic and household survey 2007

5. Begum S,Haque MM,Nasreen SA . Contraceptive Prevalence:Experience from rural Bangladesh .Mymensingh Medical Journal: July 2006 Vol 15 No 2:124127.

6. Bangladesh fertility survey 1989.

7. George C Zaidan ; The costs and benefits of family planning programs, pp43.

8. Bangladesh maternal health service and maternal mortality survey 2001

9. Bangladesh Demographic and household survey 199394 and 1996-97.
10. Journal of Obstet and Gynaecol Res. Vol. 29, no.4:268275, August 2003

11. An alternative strategy to reduce maternal mortality; A Costello and others: Published on line September28, 2006: DOI: 10.1016/ S0140-7776736(06)69388-4.

12. O M R Campbell and others ;Strategies for reducing mortality: getting on with what works, The Lancet ;Maternal Survival Series steering group, Maternal Survival, September , 2006

13. Royston E, Armstrong $S$ (editors).Preventing maternal deaths. Geneva: World Health Health organization, 1989.pp 45. 